\title{
Neuroendocrine carcinoma of the breast: a review of 126 cases in China
}

\author{
Yiqun Li, Feng Du, Wenjie Zhu and Binghe $\mathrm{Xu}^{*}$
}

\section{Dear editor,}

Neuroendocrine carcinoma of the breast (NECB) accounts for approximately $0.3 \%-0.5 \%$ of all breast cancers $[1,2]$. Due to the rarity of NECB, current understanding of this disease in China is limited to case reports and small case series, and large data analysis is still lacking. Therefore, we conducted the most comprehensive literature search to date, aiming to analyze the clinicopathologic characteristics as well as treatment and outcome of NECB in the Chinese population.

In the present study, we reported seven NECB cases diagnosed between 1990 and 2015 at the National Cancer Center \& Cancer Hospital, Chinese Academy of Medical Sciences and Peking Union Medical College, Beijing, China. Additionally, we performed a literature search of the Wanfang and Weipu databases (using the following key words: breast, neuroendocrine, tumor/carcinoma/ neoplasm/cancer, primary tumor/carcinoma/neoplasm/ cancer, and breast tumor/carcinoma/neoplasm/cancer). Articles published between 2003 and 2015 were collected and reviewed (Table 1). NECB case reports published in non-Chinese journals were not included in this study. The diagnosis was confirmed if (a) more than 50\% of the tissue specimens exhibited neuroendocrine markers, and (b) ductal carcinoma in situ was identified and/ or imaging examinations and extramammary sites were excluded. Descriptive statistics were calculated for epidemiologic, clinical, and pathologic features, for treatment, and for follow-up.

The main clinicopathologic features of the seven cases diagnosed at our hospital are summarized in Table 2 . There were six female patients and one male patient. The median age was 49 years (range, 33-78 years). All patients presented with breast lump, and one patient developed skin ulceration. Five of seven patients had the

\footnotetext{
*Correspondence: xubingheBM@163.com

Department of Medical Oncology, National Cancer Centre/Cancer Hospital, Chinese Academy of Medical Sciences and Peking Union Medical College, Beijing 100021, P. R. China
}

well-differentiated subtype of disease, and two patients had poorly-differentiated disease. Five patients had earlystage disease of luminal subtype. Six patients received chemotherapy and surgery, whereas one patient received chemotherapy alone. Patients with positive estrogen receptors (ERs) received endocrine therapy. The followup time ranged from 31 to 59 months. Five patients were alive without tumor at the last follow-up, one died of other causes, and one was lost to follow-up.

Our literature search yielded 126 cases of NECB, including our own. We analyzed the clinicopathologic features of 126 NECB cases in China (Table 3). The patients' average age was 53.2 years; there were seven male patients (5.6\%) and 119 female patients (94.4\%). Almost all patients $(124 / 126,98.4 \%)$ presented with a breast lump; six patients (4.8\%) had bloody nipple discharge. No unique appearance of NECB was identified on 85 patients who underwent ultrasound examination or 66 patients who underwent mammography examination. Most patients (100/126, 79.4\%) underwent mastectomy. A small percentage of patients $(18 / 126,14.3 \%)$ underwent breast-conserving surgery. Seven patients (5.5\%) underwent breast surgery; however, the exact type of surgical procedures was not provided in the corresponding reports. One patient $(0.8 \%)$ received chemotherapy alone. Overall, 55 patients received adjuvant chemotherapy; of these, 53 were initially treated with regimens for infiltrative ductal carcinoma (IDC) of the breast, including 51 receiving anthracycline- and taxane-based regimens and two receiving etoposide- and cisplatin-based regimens, and two were initially treated with the commonly used regimens for small cell carcinoma (Table 4).

According to the 2012 World Health Organization (WHO) classification, 52 cases were well-differentiated, and 26 were poorly-differentiated, the remaining 48 had no information of pathology. The percentages of patients with different stage breast cancer were as follows: stage I, 23.8\% (30 of 126); stage II, $47.6 \%$ (60 of 126); stage III, $11.1 \%$ (14 of 126 ); and stage IV, 3.2\% (4 of 126); the 
Table 1 Summary of published articles about neuroendocrine carcinoma of the breast included in this study

\begin{tabular}{|c|c|c|c|}
\hline Year & Author & $\begin{array}{l}\text { Number of } \\
\text { cases }\end{array}$ & Publication information \\
\hline 2005 & Zhang et al. & 5 & Zhongguo Zhongliu Linchuang 2005, 32 (13) \\
\hline 2008 & Zhong et al. & 3 & Zhongguo Xiandai Yiyao Zazhi 2008, 10 (7) \\
\hline 2008 & Zhou et al. & 7 & Lingnan Xiandai Linchuang Waike 2008, 8 (6) \\
\hline 2008 & Cui et al. & 3 & Zhongguo Shiyong Waike Zazhi 2008, 28 (7) \\
\hline 2009 & Lv et al. & 1 & Guoji Waikexue Zazhi 2009, 36 (7) \\
\hline 2009 & Ren et al. & 1 & Zhongguo Aizheng Zazhi 2009, 19 (5) \\
\hline 2009 & Guan et al. & 1 & Zhenduan Binglixue Zazhi 2009, 16 (6) \\
\hline 2010 & Zhang et al. & 1 & Zhonghua Putongwaike Zazhi 2010, 25 (12) \\
\hline 2010 & Shi et al. & 1 & Anmoyukangfu Yixue 2010, 01 (7) \\
\hline 2010 & Wang et al. & 1 & Zhonghua Ruxianbing Zazhi 2010, 04 (1) \\
\hline 2010 & Zhang et al. & 1 & Hanshao Jibing Zazhi 2010, 17 (5) \\
\hline 2010 & Shen et al. & 1 & Zhonghua Putongwaike Zazhi 2010, 25 (10) \\
\hline 2010 & Geng et al. & 3 & Dalian Yikedaxue Xuebao 2010, 32 (4) \\
\hline 2010 & Jia et al. & 6 & Guangdong Yixue 2010, 31 (17) \\
\hline 2011 & Zeng et al. & 3 & Linchuang Yu Shiyanbinglixue Zazhi 2011, 27 (6) \\
\hline 2011 & Kuang et al. & 2 & Shiyong Yixue Zazhi 2011, 27 (7) \\
\hline 2011 & Gao et al. & 16 & Zhonghua Binglixue Zazhi 2011, 40 (9) \\
\hline 2012 & Li et al. & 1 & Aizhengjinzhan 2012, 10 (3) \\
\hline 2012 & Zhang et al. & 4 & Hainan Yixue 2012, 23 (15) \\
\hline 2012 & Zhang et al. & 32 & Zhongguo Zhongliu Linchuang 2012, 39 (1) \\
\hline 2013 & Zhang et al. & 1 & Zhongwai Jiankang Wenzhai 2013, 10 (4) \\
\hline 2013 & Gu et al. & 3 & Bengbuyixueyuan Xuebao 2013, 38 (2) \\
\hline 2013 & Pan et al. & 8 & Zhongliu 2013, 33 (2) \\
\hline 2014 & Zhong et al. & 1 & Zhonghua Laonianxue Zazhi 2014, 34 (16) \\
\hline 2014 & Hou et al. & 2 & ZhongliuJichu Yu Linchuang 2014, 27 (3) \\
\hline 2014 & Yu et al. & 4 & Linchuang ChaoshengYixue Zazhi 2014, (8) \\
\hline 2015 & Huang et al. & 7 & ZhongliuYanjiu Yu Linchuang 2015, 27 (7) \\
\hline
\end{tabular}

$N E C B$ neuroendocrine carcinoma of the breast

Table 2 Clinicopathologic features of seven patients with neuroendocrine carcinoma of the breast

\begin{tabular}{|c|c|c|c|c|c|c|c|c|}
\hline No. & $\begin{array}{l}\text { Age } \\
\text { (years) }\end{array}$ & Sex & Symptom & Histology & TNM stage & Intrinsic subtype & Treatment & Follow-up outcome \\
\hline 1 & 49 & $\mathrm{~F}$ & Breast lump & Well-differentiated & T2NOMO, $\| \mathrm{A}$ & $\mathrm{ER} 3+\mathrm{PR} 2+\mathrm{HER} 2-$ & $\begin{array}{l}\text { Surgery, chemotherapy, } \\
\text { and endocrine therapy }\end{array}$ & Alive without tumor \\
\hline 2 & 78 & $\mathrm{~F}$ & Breast lump & Well-differentiated & T1N0M0, IA & $\mathrm{ER} 3+\mathrm{PR} 3+\mathrm{HER} 2-$ & $\begin{array}{l}\text { Surgery, chemotherapy, } \\
\text { and endocrine therapy }\end{array}$ & Died of other causes \\
\hline 3 & 49 & $F$ & Breast lump & Poorly-differentiated & T2NOMO, $\| \mathrm{A}$ & $\mathrm{ER} 3+\mathrm{PR}+\mathrm{HER} 2-$ & $\begin{array}{l}\text { Surgery, chemotherapy, } \\
\text { and endocrine therapy }\end{array}$ & Alive without tumor \\
\hline 4 & 58 & $\mathrm{~F}$ & Breast lump & Well-differentiated & T2N1M0, IIB & $\mathrm{ER} 2+\mathrm{PR} 2+\mathrm{HER} 2-$ & $\begin{array}{l}\text { Surgery, chemotherapy, } \\
\text { and endocrine therapy }\end{array}$ & Alive without tumor \\
\hline 5 & 43 & $\mathrm{~F}$ & $\begin{array}{l}\text { Breast lump and } \\
\text { skin ulceration }\end{array}$ & Well-differentiated & T3N2M0, IIIA & ER-PR-HER2- & $\begin{array}{l}\text { Surgery and chemo- } \\
\text { therapy }\end{array}$ & Alive without tumor \\
\hline 6 & 60 & M & Breast lump & Poorly-differentiated & T4N0M1, IV & $\mathrm{ER}-\mathrm{PR}-\mathrm{HER} 2-$ & Chemotherapy & Lost to follow-up \\
\hline 7 & 33 & $\mathrm{~F}$ & Breast lump & Well-differentiated & $\mathrm{T} 2 \mathrm{~N} 1 \mathrm{M} 0, \| \mathrm{B}$ & $\mathrm{ER} 3+\mathrm{PR} 2+\mathrm{HER} 2-$ & $\begin{array}{l}\text { Surgery, chemotherapy, } \\
\text { and endocrine therapy }\end{array}$ & Alive without tumor \\
\hline
\end{tabular}

These patients were diagnosed and treated at the National Cancer Center/Cancer Hospital, Chinese Academy of Medical Sciences and Peking Union Medical College, China

$F$ female, $M$ male, ER estrogen receptor, $P R$ progesterone receptor, HER2 human epidermal growth factor receptor 2 
Table 3 Clinicopathologic features of 126 patients with neuroendocrine carcinoma of the breast in China

\begin{tabular}{|c|c|}
\hline Characteristic & No. of cases (\%) \\
\hline \multicolumn{2}{|l|}{ Age (years) } \\
\hline$<50$ & $26(20.6)$ \\
\hline $50-59$ & $19(15.1)$ \\
\hline $60-69$ & $11(8.7)$ \\
\hline 70-79 & $7(5.6)$ \\
\hline Data unstratified & $63(50.0)$ \\
\hline \multicolumn{2}{|l|}{ Gender } \\
\hline Female & $119(94.4)$ \\
\hline Male & $7(5.6)$ \\
\hline \multicolumn{2}{|l|}{ Symptom } \\
\hline Breast lump & $124(98.4)$ \\
\hline Bloody nipple discharge & $6(4.8)$ \\
\hline Nipple erosion & $1(0.8)$ \\
\hline Dimple sign & $1(0.8)$ \\
\hline Skin ulceration & $1(0.8)$ \\
\hline \multicolumn{2}{|l|}{ Diagnostic examination } \\
\hline Biopsy before surgery & $25(19.8)$ \\
\hline Breast ultrasound & $85(67.5)$ \\
\hline Mammography & $66(52.4)$ \\
\hline Breast MRI & $1(0.8)$ \\
\hline Chest X-ray & $39(31.0)$ \\
\hline \multicolumn{2}{|l|}{ Whole body check } \\
\hline Abdominal ultrasound & $60(47.6)$ \\
\hline Abdominal CT & $1(0.8)$ \\
\hline Chest $\mathrm{CT}$ & $1(0.8)$ \\
\hline Pelvic ultrasound & $7(5.6)$ \\
\hline $\mathrm{PET} / \mathrm{CT}$ & $1(0.8)$ \\
\hline \multicolumn{2}{|l|}{ Histology } \\
\hline Well-differentiated (non-small cell) & $52(41.3)$ \\
\hline Poorly-differentiated (small cell) & $26(20.6)$ \\
\hline NM & $48(38.1)$ \\
\hline \multicolumn{2}{|l|}{ T category } \\
\hline $\mathrm{T} 1$ & $29(23.0)$ \\
\hline $\mathrm{T} 2$ & $39(31.0)$ \\
\hline T3 & $24(19.0)$ \\
\hline $\mathrm{T} 4$ & 8 (6.3) \\
\hline NM & $26(20.6)$ \\
\hline \multicolumn{2}{|l|}{ N category } \\
\hline No & 49 (38.9) \\
\hline N1 & $12(9.5)$ \\
\hline N2 & $6(4.8)$ \\
\hline N3 & $1(0.8)$ \\
\hline NM & $58(46.0)$ \\
\hline \multicolumn{2}{|l|}{ M category } \\
\hline Mo & $122(96.8)$ \\
\hline M1 & $4(3.2)$ \\
\hline \multicolumn{2}{|l|}{ TNM stage } \\
\hline 1 & $30(23.8)$ \\
\hline$\|$ & $60(47.6)$ \\
\hline
\end{tabular}

Table 3 continued

\begin{tabular}{lc}
\hline Characteristic & No. of cases (\%) \\
\hline III & $14(11.1)$ \\
IV & $4(3.2)$ \\
NM & $18(14.3)$ \\
Estrogen receptor status & \\
Positive & $102(81.0)$ \\
Negative & $23(18.2)$ \\
NM & $1(0.8)$ \\
Progesterone receptor status & \\
Positive & $91(72.2)$ \\
Negative & $34(27.0)$ \\
NM & $1(0.8)$ \\
HER2 status & \\
Overexpressed & $19(15.1)$ \\
Not overexpressed & $104(82.5)$ \\
NM & $3(2.4)$
\end{tabular}

$M R I$ magnetic resonance imaging, $C T$ computed tomography, PET positron emission tomography, HER human epidermal growth factor receptor, $N M$ not mentioned

Table 4 Treatment and follow-up of 126 patients with neuroendocrine carcinoma of the breast in China

\begin{tabular}{lc} 
Treatment and follow-up & No. of cases (\%) \\
\hline Surgery & \\
Mastectomy & $100(79.4)$ \\
Breast-conserving surgery & $18(14.3)$ \\
Other breast surgery & $7(5.5)$ \\
No surgery (chemotherapy alone) & $1(0.8)$ \\
Axillary lymph node dissection & $104(82.5)$ \\
Neoadjuvant therapy & \\
Received & $4(3.2)$ \\
None & $122(96.8)$ \\
Adjuvant therapy & \\
Chemotherapy & $55(43.7)$ \\
Infiltrative ductal carcinoma of the breast regimen & $53(42.1)$ \\
Small cell carcinoma regimen & $2(1.6)$ \\
Radiotherapy & $22(17.5)$ \\
Endocrine therapy & $80(63.5)$ \\
Tamoxifen & $71(56.3)$ \\
Aromatase inhibitors & $4(3.2)$ \\
Tamoxifen followed by aromatase inhibitors & $1(0.8)$ \\
Regimen not mentioned & $4(3.2)$ \\
Follow-up & \\
Alive without tumor & $101(80.2)$ \\
Alive with tumor & $9(7.1)$ \\
Died of disease & $7(5.6)$ \\
Died of other causes & $1(0.8)$ \\
Lost to follow-up & $8(6.3)$ \\
\hline & \\
\hline
\end{tabular}


remaining 18 had no information about pathology. ER and progesterone receptor were present in $102(81.0 \%)$ and 91 (72.2\%) patients, respectively; and human epidermal growth factor receptor 2 (HER2) protein was overexpressed in 19 (15.1\%) patients.

All cases were positive for at least one of the neuroendocrine markers (chromogranin A [CgA], synaptophysin [Syn], and neuron-specific enolase [NSE]) in more than $50 \%$ of tumor cells. Table 3 summarizes the clinicopathologic features of the 126 cases.

The follow-up time ranged from 4 to 144 months. Disease recurrence was found in 13 cases, including 4 small cell type (poorly-differentiated) cases and 9 non-small cell type (well-differentiated) cases. Seven patients died of NECB, of which four had small cell type disease and three had non-small cell type disease. The treatment and follow-up of the 126 cases are shown in Table 4.

For NECB patients in China, we determined an average age of 53.2 years, which seems to be older than the onset of IDC [3]. Six patients in our study presented with bloody nipple discharge. Kawasaki et al. [4] examined the pathology of 89 patients who came to the hospital for a thorough examination of symptomatic bloody nipple discharge and found that 24 (27.0\%) of them had neuroendocrine carcinomas. NECB may account for an important share of breast conditions associated with bloody nipple discharge. In previous reports, NECB showed no difference when compared with IDC based on imaging [5, 6], which was confirmed in the present study. In addition, in our study, most NECB cases showed positive ER expression, which supported the results of recent studies on gene expression profiling [7], suggesting that NECB belongs to the luminal type.

Currently, there is no standard therapy for NECB. Most treatments of NECB reported in the literature and in the present study are similar to the treatment of ductal-type carcinoma, with surgery as the first-line therapy, followed by anthracycline- and taxane-based chemotherapy and endocrine therapy $[1,8]$. However, whether NECB patients can benefit from chemotherapy is unknown. Current data provide little evidence to support the use of regimens for either small cell or non-small cell carcinoma.

Conflicting results of the prognosis of patients with NECB have been reported [8-10]. Among 126 Chinese cases included in the present study, nine of 18 patients (50.0\%) with the small cell carcinoma were alive without tumor relapse, whereas the percentage was $85.0 \%$ (51/60) for those with non-small cell carcinoma. Overall, $57.1 \%$ (4/7) of patients who died of NECB had small cell breast cancer.

In summary, since NECB was first listed by the WHO in 2003 as a separate unique category, many NECB cases remain to be elucidated about their etiology and treatment. In this study, we found that the onset age of
NECB patients in China seems to be older than that of IDC patients. Bloody nipple discharge may indicate the existence of NECB. Most NECB patients have the luminal subtype disease. Surgery is used as the first-line therapy, and the role of chemotherapy is still unknown. The small cell subtype may be associated with more frequent relapse and a higher mortality compared with the nonsmall cell subtype.

\section{Abbreviations}

NECB: neuroendocrine carcinoma of the breast; IDC: infiltrative ductal carcinoma; WHO: World Health Organization; ER: estrogen receptor; HER2: human epidermal growth factor receptor 2; CgA: chromogranin A; Syn: synaptophysin; NSE: neuron specific enolase.

\section{Authors' contributions}

BX conceived of and designed the study; YL conducted the literature search, performed data extraction, and wrote the manuscript; WZ performed data analysis; and FD contributed to the revising of the manuscript. All authors read and approved the final manuscript.

\section{Acknowledgements}

No grants supported this study.

\section{Competing interests}

The authors declare that they have no competing interests.

Received: 10 June 2016 Accepted: 30 December 2016

Published online: 11 May 2017

\section{References}

1. Lopez-Bonet E, Alonso-Ruano M, Barraza G, Vazquez-Martin A, Bernado L, Menendez JA. Solid neuroendocrine breast carcinomas: incidence, clinico-pathological features and immunohistochemical profiling. Oncol Rep. 2008;20(6):1369-74.

2. Gunhan-Bilgen I, Zekioglu O, Ustun EE, Memis A, Erhan Y. Neuroendocrine differentiated breast carcinoma: imaging features correlated with clinical and histopathological findings. Eur Radiol. 2003;13(4):788-93.

3. Fan L, Strasser-Weippl K, Li JJ, St Louis J, Finkelstein DM, Yu KD, et al. Breast cancer in China. Lancet Oncol. 2014;15(7):e279-89.

4. Kawasaki T, Mochizuki K, Yamauchi H, Yagata H, Kondo T, Tsunoda H, et al. High prevalence of neuroendocrine carcinoma in breast lesions detected by the clinical symptom of bloody nipple discharge. Breast. 2012;21(5):652-6.

5. Richter-Ehrenstein C, Arndt J, Buckendahl AC, Eucker J, Weichert W, Kasajima A, et al. Solid neuroendocrine carcinomas of the breast: metastases or primary tumors? Breast Cancer Res Treat. 2010;124(2):413-7.

6. Rovera F, Masciocchi P, Coglitore A, La Rosa S, Dionigi G, Marelli M, et al. Neuroendocrine carcinomas of the breast. Int J Surg. 2008;6(Suppl 1):S113-5.

7. Shin SJ, De Lellis RA, Ying L, Rosen PP. Small cell carcinoma of the breast: a clinicopathologic and immunohistochemical study of nine patients. Am J Surg Pathol. 2000;24(9):1231-8.

8. Wei B, Ding T, Xing Y, Wei W, Tian Z, Tang F, et al. Invasive neuroendocrine carcinoma of the breast: a distinctive subtype of aggressive mammary carcinoma. Cancer. 2010;116(19):4463-73.

9. Tian Z, Wei B, Tang F, Wei W, Gilcrease MZ, Huo L, et al. Prognostic significance of tumor grading and staging in mammary carcinomas with neuroendocrine differentiation. Hum Pathol. 2011:42(8):1169-77.

10. Cloyd JM, Yang RL, Allison KH, Norton JA, Hernandez-Boussard T, Wapnir IL. Impact of histological subtype on long-term outcomes of neuroendocrine carcinoma of the breast. Breast Cancer Res Treat. 2014;148(3):637-44 